\title{
Frequency of chromosomal abnormalities in miscarriages and perinatal deaths
}

\author{
EVA D. ALBERMAN AND M. R. CREASY \\ From Paediatric Research Unit, Prince Philip Laboratories, Guy's Hospital Medical School, London
}

There is a very high mortality among human conceptuses before, during, and shortly after birth, which is known as reproductive loss or pregnancy wastage. Chromosomal abnormalities are among the most important causes, particularly in the developed countries. The expulsion from the uterus of a conceptus before it is potentially sufficiently mature to survive is described as a spontaneous abortion, miscarriage, or early fetal death. In the United Kingdom viability is conventionally assumed to be attained by the 28th week after the first day of the mother's last menstrual period, though in many other countries 22 or 24 weeks is considered a more realistic time. The delivery of a dead fetus after this stage of pregnancy is known as a stillbirth or late fetal death. The death of a stillborn fetus may have occurred before or during the delivery. Intrapartum death generally results in the delivery of a fresh fetus ('fresh stillbirth'), while fetuses which die antepartum show varying degrees of maceration ('macerated stillbirth'). The death of an infant within a week of birth is an early neonatal death, and stillbirth and early neonatal death combined are termed perinatal death.

\section{Prevalence of chromosomal anomalies}

Table 1 shows the prevalence of chromosome abnormalities in spontaneously aborted fetuses (Creasy et al., 1976) in infants dying during the perinatal period (Bauld et al., 1974; Machin and Crolla, 1974; Kuleshov, 1976) and in liveborn infants (Ratcliffe, 1975). There has been a considerable variation between the prevalence of abnormal karyotypes reported by different studies: the major factor influencing the proportion of abnormalities being the gestational age of the abortuses. Of the larger studies, those that included abortuses expelled up until the end of the second trimester revealed 20 to $30 \%$ abnormal karyotypes (Carr, 1967; Dhadial et al., 1970; Creasy et al., 1976) while those studies restricted to the earlier stages of pregnancy revealed 50 to $60 \%$ of abnormalities (Therkelsen et al., 1973; Arakaki and Waxman, 1970; Kajii et al., 1973; Boué et al., 1975). From these reports it appears that the prevalence of chromosomal abnormalities in abortuses decreases from over $60 \%$ in the earliest detectable stages of pregnancy to below $5 \%$ by the end of the sixth month. About half of the chromo-

Table 1 Number and type of chromosomal anomalies found in spontaneous abortions, stillbirths, neonatal deaths, and livebirths of known karyotype

\begin{tabular}{|c|c|c|c|c|c|c|c|c|c|c|c|}
\hline & \multirow{2}{*}{\multicolumn{2}{|c|}{$\begin{array}{l}\text { Spontaneous } \\
\text { abortions* }\end{array}$}} & \multicolumn{4}{|c|}{ Stillbirths $\dagger$} & \multirow{2}{*}{\multicolumn{2}{|c|}{$\begin{array}{l}\text { Neonatal } \dagger \\
\text { deaths }\end{array}$}} & \multicolumn{3}{|c|}{ Livebirths ${ }_{+}^{\dagger}$} \\
\hline & & & \multicolumn{2}{|c|}{ Macerated } & \multicolumn{2}{|c|}{ Fresh } & & & \multirow{2}{*}{ No. } & \multirow{2}{*}{$\%$} & \multirow{2}{*}{$\begin{array}{l}\text { Prevalence } \\
\text { per } 1000\end{array}$} \\
\hline & No. & $\%$ & No. & $\%$ & No. & $\%$ & No. & $\%$ & & & \\
\hline Total number karyotyped & 983 & - & 61 & - & 222 & - & 551 & 一 & 43558 & & \\
\hline Total abnormal & 287 & 100 & 7 & 100 & 10 & 100 & 31 & 100 & 247 & 100 & $5 \cdot 69$ \\
\hline $45, X$ & 68 & $23 \cdot 7$ & 0 & & 0 & & 2 & 6.5 & 2 & 0.8 & 0.05 \\
\hline Autosomal trisomy & 143 & $49 \cdot 8$ & 3 & $42 \cdot 9$ & 7 & $70 \cdot 0$ & 17 & $54 \cdot 8$ & 52 & $21 \cdot 1$ & $1 \cdot 19$ \\
\hline Triploidy & 38 & $13 \cdot 2$ & 1 & $14 \cdot 3$ & 0 & & 1 & $3 \cdot 2$ & 1 & 0.4 & 0.02 \\
\hline Tetraploidy & 12 & $4 \cdot 2$ & 0 & & $\mathbf{0}$ & & 0 & & 0 & & 0 \\
\hline \multicolumn{12}{|l|}{ Structural: } \\
\hline balanced & 1 & $0 \cdot 3$ & 0 & & 1 & $10 \cdot 0$ & 2 & 6.5 & 80 & $32 \cdot 4$ & 1.84 \\
\hline unbalanced & 9 & $3 \cdot 1$ & & & & & 5 & $16 \cdot 1$ & 8 & $3 \cdot 2$ & $0 \cdot 18$ \\
\hline Others & 13 & $4 \cdot 5$ & 0 & & 0 & & 1 & $3 \cdot 2$ & 13 & $5 \cdot 3$ & $0 \cdot 30$ \\
\hline
\end{tabular}

*Creasy et al., 1976.

† Machin and Crolla, 1974; Bauld et al., 1974; Kuleshov, 1976.

†Adapted from Tables 5-9 (Ratcliffe, 1975). 
somally abnormal abortuses are trisomic for an autosome. Trisomies of all the autosomes except numbers 1 and 17 have been reported, though they occur with very different frequencies: trisomy 16 alone accounting for about one-third of the condition (Kajii et al., 1973; Therkelsen et al., 1973; Ikeuchi et al., 1975; McConnell and Carr, 1975; Creasy et al., 1976). Sex chromosome monosomy constitutes about a fifth of the abnormal karyotypes, but other sex chromosome abnormalities are very rare in abortuses. Triploidy occurs in about 10 to $15 \%$ of the abnormals, while the remainder are mostly tetraploids, unbalanced translocations, double trisomies, and mosaics.

The chromosome abnormalities found in perinatal deaths are similar in type to those found in newborns, but are about 10 times more common. The highest prevalence is among the macerated stillbirths, $11.5 \%$, which is more than double that of the fresh stillbirths, $4.5 \%$, and early neonatal deaths, $5.6 \%$. The abnormalities reported have been predominantly trisomy 18,13 , and 21 , sex chromosome aneuploidy and unbalanced translocations. One macerated stillbirth was trisomic for chromosome 22, and another macerated stillbirth and an early neonatal death were triploid.

The figures in Table 2 represent an attempt to extrapolate from these studies to the situation in a cohort of 1000 conceptions. Retrospective studies indicate that about $15 \%$ of clinically recognised pregnancies abort spontaneously (e.g. Warburton and Fraser, 1964), though studies employing life table techniques suggest the true figure may be 24 to $27 \%$ (French and Bierman, 1962; Erhardt, 1963). Table 2 is based on the more conservative assumption that from 1000 diagnosed pregnancies, 150 abort spontaneously, 10 are stillborn, and of the 840 remaining livebirths, 10 die during the first week of life. Fifty per cent of the spontaneous abortions are assumed to be chromosomally abnormal and thes? prevalence among perinatal deaths and livebirths iso as shown in Table 1. These calculations suggest thato in at least $8 \%$ of the diagnosed pregnancies then conceptus is chromosomally abnormal.

From these figures estimates of the previablen mortality and the perinatal mortality were made for each type of chromosome abnormality (Table 3 ). These estimates are subject to large errors because of the assumptions made and, in the case of perinataf mortality, the small numbers that have been studied $\overline{3}$ All chromosome abnormalities have a very higk? previable mortality, with the exception of sex chromo- $\overrightarrow{-}$ some abnormalities other than sex chromosomer monosomy, and balanced structural anomalies $\omega$ The mortality of autosomal trisomies varies from $_{0}^{\omega}$ about $70 \%$ for trisomy 21 , to over $90 \%$ for trisomies 13 and 18 , and virtually $100 \%$ for all others.

The estimates of perinatal mortality are, as stated, based on a small number of infants. Sex chromosomeo monosomy again has a much higher death rate than other sex chromosome abnormalities. This is in line with a report by Robinson (1974) who found a $33 \%$ early neonatal mortality for $45, \mathrm{X}$ infants $(3 / 9)$ compared with $13 \%$ for those with sex chromosomeo trisomy (4/31) detected by sex chromatin analysis of neonates. The perinatal mortality of trisomy 13 and $\overline{0}$ particularly, 18 is much higher than that of trisomyo 21 , being over $90 \%$ for the two former and only abouto $12 \%$ for the latter trisomy. In fact, the perinata $\vec{F}$ mortality of trisomy 18 was estimated as over $100 \%, 3$ which has been interpreted by Machin and Crolla (1974) as indicating that this condition is more com? mon at term than is generally believed. The estimate for triploidy may be too low, as only one non-mosaico

Table 2 Estimated numbers of abnormal fetuses which are aborted, stillborn, liveborn, and which die neonatally from a cohort of 1000 pregnancies by karyotype

\begin{tabular}{|c|c|c|c|c|c|}
\hline & \multirow{2}{*}{$\begin{array}{l}1 \\
\text { Spontaneous } \\
\text { abortions }\end{array}$} & \multicolumn{2}{|l|}{ Stillbirths } & \multirow{2}{*}{$\begin{array}{l}4 \\
\text { Neonatal deaths } \\
\text { (incl. in } L B \text { ) }\end{array}$} & \multirow{2}{*}{$\begin{array}{l}5 \\
\text { Livebirths }\end{array}$} \\
\hline & & $\begin{array}{l}2 \\
\text { Macerated }\end{array}$ & $\begin{array}{l}3 \\
\text { Fresh }\end{array}$ & & \\
\hline \multicolumn{6}{|l|}{$\begin{array}{l}\text { Number assumed to } \\
\text { be derived from }\end{array}$} \\
\hline 1000 pregnancies & 150 & 5 & 5 & (10) & 840 \\
\hline Total abnormal & $75 \cdot 0$ & 0.57 & $0 \cdot 23$ & $(0.56)$ & $4 \cdot 78$ \\
\hline 45, $X$ & $17 \cdot 77$ & 0 & 0 & $(0.036)$ & 0.039 \\
\hline Other sex aneuploidy & 0.78 & $0 \cdot 25$ & 0.05 & $(0.05)$ & $1 \cdot 76$ \\
\hline Autosomal trisomy & $37 \cdot 37$ & $0 \cdot 25$ & $0 \cdot 16$ & $(0 \cdot 31)$ & 1.00 \\
\hline Triploidy & 9.93 & 0.08 & 0 & $(0.02)$ & 0.02 \\
\hline Tetraploidy & $3 \cdot 14$ & 0 & 0 & (0) & 0 \\
\hline \multicolumn{6}{|l|}{ Structural: } \\
\hline balanced & 0.26 & $\mathbf{0}$ & 0.02 & $(0 \cdot 04)$ & 1.55 \\
\hline unbalanced & $2 \cdot 35$ & $\mathbf{0}$ & 0 & $(0.09)$ & 0.15 \\
\hline Others & 3.40 & 0 & 0 & $(0.02)$ & 0.25 \\
\hline Normal & $75 \cdot 0$ & 4.43 & $4 \cdot 77$ & $(9 \cdot 44)$ & $835 \cdot 22$ \\
\hline
\end{tabular}

LB, livebirths. 
Table 3 Previable mortality and perinatal mortality* derived from figures in Table $2 \dagger$

\begin{tabular}{lcc}
\hline & $\begin{array}{l}\text { Previable } \\
\text { mortality } \%\end{array}$ & $\begin{array}{l}\text { Perinatal } \\
\text { mortality } \%\end{array}$ \\
\hline Assumed overall mortality & 15 & $2 \cdot 4$ \\
Total abnormal & $93 \cdot 1$ & $24 \cdot 4$ \\
45, X & $99 \cdot 8$ & $94 \cdot 2$ \\
Other sex aneuploidy & $27 \cdot 5$ & $17 \cdot 0$ \\
Autosomal trisomy & $96 \cdot 4$ & $51 \cdot 1$ \\
Triploidy & $98 \cdot 8$ & $98 \cdot 8$ \\
Tetraploidy & $100 \cdot 0$ & - \\
Structural: & $14 \cdot 2$ & $3 \cdot 8$ \\
$\quad$ balanced & $94 \cdot 0$ & 60.0 \\
$\quad$ unbalanced & $93 \cdot 2$ & $8 \cdot 0$ \\
Others & $8 \cdot 16$ & $2 \cdot 2$ \\
\hline
\end{tabular}

* Large standard errors due to small numbers, particularly for perinatal deaths.

$\dagger$ Previable mortality $=\frac{\text { col } 1}{\operatorname{col} 1+2+3+5} \times 100$
Perinatal mortality $=\frac{\operatorname{col} 2+3+4}{\operatorname{col} 2+3+5} \times 100$

triploid has survived beyond the early neonatal period, and that died at 9 days (de Grouchy et al., 1974). As with the abortuses the unbalanced translocations have a much higher mortality than those that are balanced.

\section{Conclusion}

In spite of the approximations involved in these calculations it is clear that the chromosome abnormalities detected in liveborn infants are only a small fraction of all aberrant conceptions, most of which die in the early stages of gestation. The low mortality of balanced structural abnormalities seems reasonable, and the Lyon hypothesis explains the relatively high survival of sex chromosome polysomies (Lyon, 1961). However, in the case of abnormalities which are sometimes compatible with survival into adult life, such as sex chromosome monosomy or trisomy 21 , we have no explanation why most zygotes are aborted, but some survive.

These estimates of the viability of various chromosomal abnormalities show that if an environmental hazard were to increase their incidence at conception uniformly only a few would reflect this in their birth prevalence, and most affected individuals would be unlikely to reproduce. Any factor which were to affect the relation between incidence and prevalence could have a very serious effect on the number of affected survivors. Heritable abnormalities, such as balanced translocations, while not producing abnormal individuals directly, could have a much greater longterm effect on the population, and would mostly evade the screening mechanism of abortion and perinatal death.

\section{References}

Arakaki, D. T., and Waxman, S. H. (1970). Chromosome abnormalities in early spontaneous abortions. Journal of Medical Genetics, 7, 118-124.

Bauld, R., Sutherland, G. R., and Bain, D. (1974). Chromosome studies in investigation of stillbirths and neonatal deaths. Archives of Disease in Childhood, 49, 782-788.

Boué, J., Boué, A., and Lazar, P. (1975). Retrospective and prospective epidemiological studies of 1500 karyotyped spontaneous human abortions. Teratology, 12, 11-26.

Carr, D. H. (1967) Chromosome anomalies as a cause of spontaneous abortion. American Journal of Obstetrics and Gynecology, 97, 283-293.

Creasy, M. R., Crolla, J. A., and Alberman, E. D. (1976). A cytogenetic study of human spontaneous abortions using banding techniques. Humangenetik, 31, 177-196.

Dhadial, R. K., Machin, A. M., and Tait, S. M. (1970). Chromosomal anomalies in spontaneously aborted human fetuses. Lancet, 2, 20-21.

Erhardt, C. L. (1963). Pregnancy losses in New York City, 1960. American Journal of Public Health, 53, 1337-1352.

French, F. E., and Bierman, J. M. (1962). Probabilities of fetal mortality. Public Health Reports, 77, 835-847.

De Grouchy, J., Roubin, M., Risse, J. C., and Sarrut, S. (1974). Enfant triploide $(69, \mathrm{XXX})$ ayant vécu neuf jours. Annales de Génétique, 17, 283-286.

Ikeuchi, T., Sasaki, M., and Fujimoto, S. (1975). Chromosome studies on spontaneous and threatened abortions. Japanese Journal of Human Genetics, 20, 245-246.

Kajii, T. Ohama, K., Niikawa, N., Ferrier, A., and Avirachan, S. (1973). Banding analysis of abnormal karyotypes in spontaneous abortions. American Journal of Human Genetics, 25, 539-547.

Kuleshov, N. P. (1976). Chromosome anomalies of infants dying during the perinatal period and premature newborn. Humangentik, 31, 151-160.

Lyon, M. F. (1961). Gene action on the X-chromosome of the mouse (Mus musculus L.). Nature, 190, 372-373.

McConnell, H. D., and Carr, D. H. (1975). Recent advances in the cytogenetic study of human spontaneous abortions. Obstetrics and Gynecology, 45, 547-552.

Machin, G. A., and Crolla, J. A. (1974). Chromosome constitution of 500 infants dying during the perinatal period. Humangenetik, 23, 183-198.

Ratcliffe, S. (1975). Postnatal chromosome abnormalities. In Chromosome Variations in Human Evolution, pp. 97-115. Ed. by A. J. Boyce. Taylor and Francis, London.

Robinson, A. (1974). Neonatal deaths and sex-chromosome anomalies. Lancet, 1, 1223,

Therkelsen, A. J., Grunnet, N., Hjort, T., Myhre Jensen, O., Jonasson, J., Lauritsen, J. G., Lindsten, J., and Bruun Petersen, G. (1973). Studies on spontaneous abortions. In Chromosomal Errors in Relation to Reproductive Failure, pp. 81-93. Ed. by A. Boué and C. Thibault. INSERM, Paris.

Warburton, D., and Fraser, F. C. (1964). Spontaneous abortion risks in man: data from reproductive histories collected in a medical genetics unit. American Journal of Human Genetics, 16, 1-25.

Requests for reprints to Dr M. R. Creasy, Paediatric Research Unit, Prince Philip Laboratories, Guy's Hospital Medical School, London SE1 9RT. 